\title{
Identidades no contemporâneo: uma reflexão a partir da narrativa audiovisual "Meia-Noite em Paris"
}

\section{Gislene Feiten Haubrich ${ }^{1}$}

\begin{abstract}
Resumo:O artigo busca compreender implicações da noção de nostalgia à representação identitária dos sujeitos na contemporaneidade, tendo como base o drama da personagem Gil Pender, na narrativa audiovisual Meia-Noite em Paris (2011), de Woody Allen. Justifica-se o estudo diante da conexão entre nostalgia e devaneio ao estudo das identidades, além da relevância atribuída pelos sujeitos ao sentimento nostálgico na reconstituição de memórias que fundamentam seu viver. Nesta perspectiva, desenvolve-se uma pesquisa exploratória, de cunho bibliográfico e enfoque em análise fílmica. O referencial teórico é composto por Bachelard (1994; 1998), que orienta o entendimento acerca de tempo e de espaço, basilares à análise da ideia de nostalgia; Hall $(2003$; 2006) para a compreensão das noções de identidade e representação. Já as linguagens fílmicas serão estudadas a partir da elucidação de Gardies (2008) e Gaudreault e Jost (2009). Assim, o estudo percebe a nostalgia enquanto convite ao transitar pelo passado para depreender o presente. $\mathrm{O}$ sentimento nostálgico permite o acesso referencial aos espaços que podem orientar a construção de certezas (sempre provisórias) às vivências dos sujeitos, sendo a representação de sua identidade resultado dessa construção intelectual.
\end{abstract}

Palavras-Chave:Tempo; Espaço; Nostalgia; Meia-Noite em Paris.

\begin{abstract}
The article aims to understand how the sense of nostalgia implies the identity's representation of the subjects in contemporary society. It based on the drama of main character, Gil Pender, of the audiovisual narrative Midnight in Paris (2011), Woody Allen. The study is justified because it promotes the connection between nostalgia and reverie to study the identity, beyond the relevance attributed by the individuals to the nostalgic feeling for the reconstitution of memories that support their life. In this perspective, it develops bibliographic and exploratory research, focused on film analysis. The theoretical framework is: Bachelard (1994; 1998), which guides to understanding of time and space, the base to the idea of nostalgia; Hall $(2003$; 2006) for understanding the notions of identity and representation. Already the filmic languages will be studied from the elucidation of Gardies (2008) and Gaudreault \& Jost (2009). Thus, the study comprehends the nostalgia like a invitation while transiting the past to infer the present. The nostalgic feeling allows referential access to spaces that can guide the construction of certainties (always provisional) the experiences of the subjects. The representation of their identity is the result of this intellectual construction.
\end{abstract}

Keywords: Time; Space; Nostalgia; Midnight In Paris

\footnotetext{
${ }^{1}$ Doutoranda, com período sanduíche na Université de Strasbourg, e mestre em Processos e Manifestações Culturais. Graduada em Comunicação Social (Feevale). E-mail: gisleneh@gmail.com
} 


\section{O túnel do tempo: percursos e movimentos no espaço discursivo}

Em meados dos anos 2000, entidades focadas em pesquisas de mercado anunciaram uma tendência para as próximas décadas: o chamado consumo "retrô". Em resposta a essa proposta, diversas marcas utilizaram essa estratégia em seus posicionamentos e na publicidade de seus produtos. Como exemplo, pode-se citar a Geladeira Brastemp Retrô Frost Free ou a reedição do Fusca pela Wolkswagen. Pode-se ainda mencionar que, no ano de 2014, diversas atividades foram registradas em comemoração aos 20 anos de exibição do primeiro episódio da série americana Friends [1], bem como os 10 anos de seu término. Para além do consumo, quais reflexões podem emergir desse interesse dos sujeitos em reviver momentos passados? Mais instigante é a disposição para "reviver" um tempo em que jamais se esteve. Afinal, é comum ouvir enunciados como: "nasci no tempo errado", "os anos 8o [leiase a década que interessar] eram demais" e tantos outros ditos adequados ao cenário instaurado no imaginário dos sujeitos das mais diversas faixas etárias.

Nesse sentido, torna-se pertinente refletir sobre tais produtos culturais que, ao assumirem características que remontam a décadas passadas, estimulam um sentimento que acompanha constantemente a vida humana: a nostalgia. Diversas são as perspectivas possíveis para uma análise do consumo nesse contexto. Para este estudo, o enfoque selecionado tange as implicações da noção de nostalgia à representação identitária dos sujeitos na contemporaneidade. Como olhar para o contemporâneo? Vive-se em um mundo globalizado e permeado por paradoxos. Ao mesmo tempo em que as fronteiras territoriais são derrubadas, elas são também reforçadas. Molda-se a clausura como escudo protetor frente ao desconhecido. Todavia, o estranho tem permissão para adentrar o espaço íntimo por meio das portas da rede mundial de computadores.

Essas percepções sustentam o pressuposto de que o desejo de reviver o passado, onde estão proteção e segurança, é compartilhado pelos sujeitos, independente do território ocupado. Diante disso, justifica-se esta investigação, uma 
vez que apresenta ponderações sobre a decorrência desse fenômeno, constante, atual e relevante à constituição da identidade.

Esta pesquisa visa compreender possíveis implicações da noção de nostalgia à representação identitária dos sujeitos na contemporaneidade, tendo como base o drama da personagem Gil Pender, na narrativa audiovisual Meia-Noite em Paris. Para tanto, discorre-se acerca das noções de tempo e de espaço que norteiam a compreensão de nostalgia, além da interface entre os pontos de vista da identidade, da representação e do hibridismo, basilares para o entendimento da contemporaneidade e das incitações do consumo ao sentimento nostálgico.

Quanto aos procedimentos metodológicos, trata-se de uma pesquisa de natureza aplicada, com abordagem qualitativa, uma vez que se busca a compreensão de fenômenos humanos e sociais, a partir de uma obra de ficção. Quanto aos procedimentos para coleta de dados, trata-se de uma pesquisa bibliográfica que busca a conversão conceitual das noções que compõem o referencial teórico, assim como a análise fílmica, a fim de compreender a escolha das representações na composição da ficção audiovisual e relacioná-las ao arcabouço teórico definido.

O marco teórico agrega a proposta de tempo e espaço em Bachelard (1994; 1998)para compreender o fenômeno da nostalgia sob o viés da narrativa audiovisual de Woody Allen, visto que reflete sobre as implicações do passado no futuro, diante do que é vivido no presente. Para refletir sobre os cenários da contemporaneidade, recorre-se à proposta de Hall (2003; 2006), cuja abordagem enfoca o hibridismo cultural e as implicações na constituição identitária do sujeito. Por fim, a análise fílmica será norteada pela proposta de Gardies (2008) e Gaudreault \& Jost (2009) que contemplam características técnicas da produção audiovisual. O artigo contempla três etapas de reflexão teórica e é finalizado perante a análise proposta.

\section{Cenários da contemporaneidade: identidade e hibridismo}

Pensar a forma como se vive na contemporaneidade implica lidar com conceitos que são, por vezes, avessos ao conforto, fixidez ou tradição, estimados por 
muitas culturas até pouco tempo. Palavras, como incerteza e medo, passaram a ter recorrência nos discursos cotidianos. Os sujeitos buscam alternativas a esses sentimentos, a fim de sanar uma das mais latentes necessidades humanas: segurança. Muitas vezes, a proteção é encontrada no passado, dada certa previsibilidade dos acontecimentos, assim como do sentido coletivo e compartilhado, da noção de humanização. Bauman (2007, p. 30) corrobora com a reflexão:

Os vínculos humanos são confortavelmente frouxos [...]. O novo individualismo, o enfraquecimento dos vínculos humanos e o definhamento da solidariedade estão gravados num dos lados da moeda, cuja outra face mostra os contornos nebulosos da globalização negativa.

A noção de globalização assume relevo, visto que traz consigo questões paradoxais: liberdade versus prisão, individualismo, o uso do outro para os próprios interesses, cooperação versus competição (BAUMAN, 2007). Hall (2006) compartilha dessa inquietude. Este autor afirma que a modernidade tardia é caracterizada pela fragmentação de questões fundamentais à formação humana, como o sentido de coletividade, de construção social de significados, além do descentramento do sujeito provido pelos múltiplos sistemas de significação, ou culturas, às quais ele é exposto (HALL, 2006).

A globalização, no olhar de Hall (2006, p. 67),

se refere àqueles processos, atuantes numa escala global, que atravessam fronteiras nacionais, integrando e conectando comunidades e organizações em novas combinações de espaço-tempo, tornando o mundo, em realidade e em experiência, mais interconectado.

Essa condição favorece o que ele chama de "crise de identidade", pois as referências tidas até então, por meio das leis religiosas, governamentais etc., passam a ser questionadas.Diante disso, as transgressões assumem evidência e favorecem o entendimento de que o comportamento do indivíduo não pode ser previsto ou antecipado, mas determinado por circunstâncias às quais ele é submetido.

Alinhada à crise identitária está outro resultado do processo globalizante: a questão multicultural. A formação heterogênea das culturas é posta à luz, já que as influências espaço-temporais ao desenvolvimento das nações são transformadas. A questão multicultural, na proposta de Hall (2003), apresenta diversas consequências, dentre as quais assume relevo, neste estudo, o hibridismo cultural, visto que se refere 
a "um termo que tem sido utilizado para caracterizar as culturas cada vez mais mistas e diaspóricas" (HALL, 2003, p. 74). O desenvolvimento dessa concepção, para Hall (2006), está ancorado na mobilidade dos indivíduos, no tempo e no espaço. Quando os povos passam a ser deslocados para outros espaços, estabelecendo comunidades diásporas, o hibridismo passa a ser uma resultante inevitável, dada a fusão entre as tradições que os sujeitos trazem de sua terra natal e o que está já fundamentado no local de chegada. A noção de hibridismo, abordada por Hall, advém de suas leituras da obra de Homi Bhabha.

A reflexão de Bhabha (1998) decorre da perspectiva dialógica do Círculo de Bakhtin, que pressupõe os interlocutores situados e contextualizados. De acordo com Bakhtin (2015), a interação verbal é como um conjunto de elos que conectam os enunciados e produzem/alteram o espaço coletivo. Essa interação é permeada por valores socialmente instituídos, vozes diversas (polifonia), forças centrípetas e centrífugas. Diante desse vínculo coletivo, ou, conforme define Bhabha (1998), do lócus de enunciação, que as noções de enunciado e enunciação assumem relevo na concepção do hibridismo. No processo de deslocamento do enunciado à enunciação está o hibridismo, pois contempla os intérpretes, ou sujeitos da linguagem, intervindo na produção e na interpretação dos significados que os conectam e os afastam.

O lócus de enunciação, de acordo com Bhabha (1998), compõe um terceiro espaço onde está situado quem fala. Ele contempla uma gama heterogênea de valores e ideologias que constituem o contexto social, além de se caracterizar como o lugar onde se dá a interpretação, a reflexão diante dos elementos linguísticos e culturais que são postos em interação. É a convergência de fatores deste lócus que permite o entendimento da noção de hibridismo. Assim, as combinações espaço-temporais decorrentes da globalização, que caracterizam o hibridismo, multiplicam os enunciados em quantidade e diversidade, o que possibilita aos indivíduos a produção de tantas representações de sua identidade quanto possam englobar. As referências de conduta são transitórias e a insegurança pode se tornar resultado deste processo de adaptação ao mundo. A fim de ampliar esta reflexão, prossegue-se o raciocínio com base nas perspectivas de tempo e de espaço. 


\section{O tecer do tempo e do espaço: inspirações bachelardianas}

A sociedade contemporânea é movimentada por paradoxos decorrentes da conversão entre o global e o local, da derrubada das fronteiras territoriais que, em oposição, pode resultar no isolamento (BAUMAN, 2007). Há, ainda, outros quadros de oposição que constroem a identidade dos sujeitos. A vivência passa a ser dual ou ambígua e, neste sentido, se opõe à mundialização, pois os enunciados que aí transitam permitem e estimulam múltiplas possibilidades representativas. No entanto, entre o paradigma e o paradoxo se percebe a sobrevivência humana no presente vinculada ao desejo de retomar o passado, dada a aflição causada pelo futuro.

Lipovetsky (2005, p. 38) afirma que "todas as lembranças, todos os universos de sentido, todos os imaginários coletivos que fazem referência ao passado são o que pode ser convocado e reutilizado para a construção de identidades e a realização pessoal dos indivíduos". Esse autor é crítico da exploração comercial do passado, a partir de uma humanização que estimula a nostalgia como elemento basilar da constituição identitária. Para Lipovetsky (2005), essa abordagem afasta os sujeitos de construções reflexivas acerca de seu futuro, conduzindo-os à construção difusa e reversa de valores e de condutas. Trata-se de um abuso do passado que garante a felicidade nos tempos hipermodernos. Felicidade tão efêmera quanto aquilo que a origina. Felicidade tão passageira quanto as tendências do mundo da moda.

A transgressão de um ponto de vista que percebe a sociedade atual a partir da decepção (LIPOVETSKY, 2007) implica visualizar a questão da nostalgia como elemento positivo à constituição identitária, uma vez que a fragmentação do tempo em passado, presente e futuro não é a única forma de entender a nostalgia contemporânea. Faz sentido, então, estabelecer uma ruptura com a visão linear do tempo para encontrar outras leituras de mundo. Desse modo, contempla-se a globalização enquanto fenômeno permanente e que pode trazer muitas pistas à compreensão dos problemas da coletividade.Para tanto, é fundamental que se reconheçam os espaços a serem percorridos, bem como a intersecção do tempo. 
A proposta de Gaston Bachelard ampara essa perspectiva. O viés poético do autor permite transcender a contemplação da vida: eleva-se a reflexão e aceita-se que tempo e espaço são ilimitados. Bachelard, inspirado na teoria da relatividade de Einstein, defende que o tempo, além de horizontal, é também vertical, o que permite uma movimentação a espaços diversos, o que significa transpor delimitações temporais lineares do relógio e do calendário.

A perspectiva bachelardiana orienta uma forma diferente de ação: transita-se no passado para compreender o presente, visto que é a materialização do futuro. Em síntese: tempo e espaço são variáveis incontroláveis e fundamentais para compreender os fenômenos sociais. Bachelard (1994) propunha, sobretudo, o rompimento com a visão fragmentada do mundo. Para ele, tal visão resulta da corrente de pensamento científica emergente no século XVI. O homem passa a ser centro do universo, posto que é o único ser capaz de dominar quaisquer aspectos da natureza, o que culmina com a supra valorização da objetividade em detrimento da subjetividade.

O tempo, para Bachelard, não é universal, mas decorre de um referencial. Na sua concepção, existem diferenças entre o tempo vivido e o tempo pensado, uma vez que possuem princípios de encadeamento diferentes, que se sobrepõem, fazendo existir um pluralismo temporal. Nas palavras do autor: "para a relatividade, há vários tempos que, sem dúvida, correspondem-se e conservam ordens objetivas de transcurso, mas que não guardam durações absolutas” (BACHELARD, 1994, p. 85). $\mathrm{Na}$ fenomenologia bachelardiana, as vivências não podem ser medidas, o que estabeleceria uma duração. Ao contrário, é a partir dos instantes, ou seja, da consciência do tempo enquanto construção do intelecto que se podem compreender as situações vividas.

Da visão descontínua do tempo advêm as ideias de tempo vivido, da ação, que podem ser sobrepostos pelo tempo pensado, do espírito. Bachelard (1994, p. 86) acredita que "o tempo do espírito tem uma ação em profundidade, em planos que não são o de seu próprio plano de transcurso". O tempo do espírito permite um contato profundo do sujeito com seu intelecto, o que proporciona um trânsito de mais qualidade nos espaços percorridos. As lacunas do tempo, percebidas diante da 
ruptura da visão linear e do estabelecimento de uma verticalização, dão liberdade ao espírito para que acesse todas as instâncias da "casa" e se produza uma noção mais real de si, do outro e do mundo.

O espaço conjugado a partir do tempo é também fundamental na obra de Bachelard. Ambas as concepções se entrelaçam para a imersão ao mais íntimo do ser, que traça, além, o rumo ao devaneio, porta principal à condução da imaginação criadora, que é sua materialidade. "Por isso, para ele, a imaginação dinamiza o ato de conhecer em seu poder constitutivo do ser humano - enquanto pensador e sonhador - essencialmente criador porque capaz de pôr em movimento ideias e imagens para investigar o real" (FRONCKOWIAK; RICHTER, 2005, p. 3). Perante a fenomenologia poética de Bachelard, para além dos meios racionalistas para compreensão dos fatos, está a imaginação criadora, tomada de liberdade produtora e (re)produtora de cenários frente ao que se quer entender.

Os pressupostos tecidos por Bachelard emergem da crença de que uma imagem poética pode ser produzida pelo indivíduo ao transitar por sua alma, posto que ela sustenta uma forma consciente, da coisa que é imaginada, materializada. Trata-se do devaneio. Novidades expressivas, que implicam o encontro dos espaços de felicidade e de proteção, são dispostas ao sujeito e edifica-se uma relação entre a casa e os espaços, íntimos e exteriores, do sujeito. "[...] A casa abriga o devaneio, a casa protege o sonhador, a casa permite sonhar em paz. Só os pensamentos e as experiências sancionam os valores humanos. Ao devaneio pertencem os valores que marcam o homem em sua profundidade" (BACHELARD, 1998, p. 26). A casa é proteção. A casa é liberdade. A casa é o reencontro do ser com os "deuses domésticos" que o acompanham durante toda a existência e que o conduzem às leituras do mundo.

A metáfora bachelardiana da casa enquanto entidade protetora e promotora do espírito humano complementa os espaços que permitem o refúgio dos deuses domésticos:as lembranças permeiam o porão e o sótão; escondem-se em cantos e corredores. "É pelo espaço e no espaço que encontramos os belos fósseis de duração concretizados por longas permanências. [...] Mais urgente que a 
determinação de datas é, para o conhecimento da intimidade, a localização nos espaços da nossa intimidade" (BACHELARD, 1998, p. 29). No entanto, é importante reencontrar as recordações constantemente, pois, para a fenomenologia poética, é deste encontro que se produz o conhecimento, que só pode ser pleno quando emergente do autoconhecimento. Tal proposta implica ir além, identificar os espaços mais próximos que ocupam as memórias, na casa e na intimidade. Esse percurso constitui o devaneio, essencial à ordem interna, o ponto de referência desvendado pelo acesso aos espaços em um tempo verticalizado.

A imagem da casa, em Bachelard (1998, p. 36), tem especificidades, conforme ele caracteriza: " $1^{\mathrm{o}}$ : A casa é imaginada como um ser vertical. Ela se eleva. Ela se diferencia no sentido de sua verticalidade. É um dos apelos à nossa consciência de verticalidade. $2^{\circ}$ : A casa é imaginada como um ser centrado. Ela nos leva a uma consciência de centralidade”. A busca pelo centro é viabilizada pela verticalização do tempo e do espaço, que permite o encontro do sujeito com suas construções mais primárias, que sustenta o devaneio. Encontrar respostas impulsiona a desvendar o desconhecido; o aprofundamento das motivações reais da conduta humana.

$\mathrm{Na}$ atualidade, os seres, tomados pela racionalidade, são privados do desenvolvimento desta habilidade de centramento, de reencontro com a intimidade e de mobilização de memórias desnudas e passíveis de reconhecimento. Nesse sentido, reconhecer tempo e espaço sob a perspectiva poética tende a fornecer possibilidades frente às dramáticas humanas, que anseiam um futuro, mas têm dificuldade de entendê-lo, pois não reconhecem as raízes de seus pensamentos.

\section{As linguagens, as imagens e os sentidos}

As narrativas audiovisuais são ferramentas excelentes para a compreensão de fenômenos da vida humana, uma vez que determinadas categorias fílmicas fixamse nas dramáticas de seu tempo. Sobretudo, na atualidade, os filmes caracterizam-se como tradutores dos sentidos cotidianos, sendo frequentemente associados às 
situações de vida dos sujeitos que encontram na ficção possíveis soluções às suas histórias.

Gaudreault e Jost (2009) esclarecem o reconhecimento de uma narrativa demanda atenção a cinco características: a) apresentar começo, meio e fim demarcados, sem responder a todas as perguntas, o que instiga a intervenção do espectador; b)compreender duas temporalidades, da coisa narrada e da narração em si; c) conter uma pluralidade de enunciados na composição do discurso narrativo; d) abordar um plano diferente do vislumbrado pelo leitor; e) a narrativa é um conjunto de acontecimentos, uma unidade fundamental. Diante disso, propõe-se que a condução da análise proceda da identificação dessas características no filme selecionado para este estudo.

Além da narrativa, que traça uma linha evolutiva diante dos momentos encadeados, o cinema dispõe de técnicas específicas para nortear o olhar do espectador, para além da imagem explícita pela construção fílmica. Gardies (2008) apresenta esses procedimentos, a iniciar pelos planos utilizados para captação das cenas, que se referem a um ponto de vista que se constitui diante de uma montagem de sons e imagens. Há, ainda, o enquadramento, cuja função é constituir um espaço de representação que delimita e organiza o ato encenado. Os parâmetros de enquadramento podem ser a composição, a encenação, a montagem e o espaço diegético que implica o cenário, a iluminação, a cor e o som selecionados diante da intencionalidade dos autores da obra.

Outro aspecto que interessante à análise fílmica refere-se à indicação do contexto, já que, conforme Gardies (2008, p. 153), “[...] são as determinações contextuais que, ao nos tornarem sujeito leitor, regem a forma como produzimos sentido". Assim, a seleção dos elementos para a construção da cena é imbuída pela intencionalidade do autor, que os escolhe mediante os significados já ratificados no espaço social. Entretanto, importa salientar que os sentidos atribuídos à sequência de estímulos audiovisuais são singular espara cada espectador. Percebe-se, então, a relevância da linguagem para esse autor, visto que ela possui funções que transcendem a transmissão de mensagens. 
De acordo com Gardies (2008) duas funções da linguagem merecem atenção. A função afetiva visa a comprometer o espectador emocionalmente, posicionando-o frente às mensagens recebidas. Já a função social de "[...] um filme aplica atos de linguagem que visam modelar nossa relação com o mundo" (GARDIES, 2008, p. 154). Por fim, a imagem também possui funções específicas frente aos sentidos que se deseja construir: a) função de representação, ou de tornar presente o que está ausente, e b) função de transformação, que implica a ação sobre o comportamento do sujeito espectador (GARDIES, 2008). Diante dessas categorias de análise fílmica, busca-se compreender a personagem de Gil Pender, mediante a relevância da nostalgia na sua representação identitária.

\section{A magia das doze badaladas: tempo e espaço na representação identitária de Gil Pender}

Do diálogo entre as perspectivas teóricas e as características técnicas, promove-se a análise da obra de Woody Allen, Meia-Noite em Paris (2011). Com base nos eventos vivenciados pela personagem Gil Pender (interpretada por Owen Wilson), observa-se a nostalgia enquanto elemento indicativo da representação identitária dos sujeitos na contemporaneidade. Caracterizada como uma narrativa clássica, essa produção audiovisual conta a história do roteirista de Hollywood, fascinado pela literatura americana dos anos 1920 - melhor época para se viver, na sua visão. A partir das cinco categorias, mencionadas por Gaudreault e Jost (2009), para o reconhecimento de uma narrativa, pode-se indicar que início, meio e fim são claramente demarcados. A narração tem início com a estada de Gil e da família de sua noiva, Inez, em Paris. Na perspectiva adotada para esta reflexão, aponta-se que o devaneio de Gil é fator que desencadeia os acontecimentos até o fechamento narrativo, com a decisão do roteirista de permanecer na França e ali reconstruir sua vida. A temporalidade é a tônica da obra cinematográfica, visto o jogo entre a coisa narrada, o devaneio, e a narração concatenada. 
A construção fílmica, além de promover reflexões acerca da representação identitária dos sujeitos, também oferece aos espectadores fotografias dos espaços que se constituem como cenário da história. A viagem realizada pelo enunciador fílmico nos primeiros minutos da produção sintetiza e demarca espaços que são fundamentais para a narrativa. Exemplifica-se: o caminho para a loja de artigos antigos, por vezes visitada por Gil; a estrada que guia o caminho do carro ao passado; os cafés e as praças onde se dão profundas reflexões da personagem sobre sua vida. A cidade com chuva. A cidade à meia-noite. Por fim, a cidade cotidiana, local que Gil escolhe para reconstituir sua vida. Toda a sequência de imagens, assim como a narrativa, é conduzida por músicas francesas dos anos 1920, som não-diegético que, conforme acena Gardies (2008),propicia contexto e aguça a memória do espectador.

Aberta às mais diversas possibilidades interpretativas, a "moral da história" explicitada pelo filme reflete sobre o apego ao passado no processo de sujeição, mas salientam viver no presente e transformar o futuro. Tal entendimento advém da avaliação das diversas linguagens utilizadas para o tecer da obra: o texto, as imagens, a sonoridade e a contextualização. Destaca-se a estratégia de reconstituição histórica, posto que o fato narrado remete à vivência de Wood Allen (diretor e roteirista do filme) fora dos EUA, o que sustenta a inclusão de elementos autobiográficos ou mesmo de autoreflexão à produção. A trama se desenvolve com a retomada do movimento diapórico de escritores americanos, que trocaram os EUA para realizar sua obra na França, em paralelo às vivências da personagem principal. Nesse sentido, as escolhas de Allen para a produção fílmica atendem às funções que a narrativa propõe (GARDIES, 2008), como, por exemplo, impulsionar vínculos emocionais que estimulam a reflexão acerca das vivências do espectador.

Diversos são os recursos técnicos utilizados para mobilizar tais sentidos (GARDIES, 2008), destacando-se o uso dos planos gerais, que dão profundidade às cenas e ênfase aos espaços percorridos, além da captura de imagens com pouca movimentação. Salienta-se, ainda, que a distância da câmera frente à situação que reproduz remete à forma como a personagem se vê, diante de um olhar externo (do devaneio) ao espaço interno. Quando o plano da imagem é aproximado, tem-se a 
quebra do devaneio, a retomada das situações cotidianas. Os planos médios e americanos são utilizados essencialmente nas situações vividas nos anos 1920, quando a cor usada para representação torna-se mais primordial e o fundo levemente desfocado. Os cenários também são adequados e apenas Gil os acessa, conduzindo à percepção de que se trata de construções decorrentes de seu transitar vertical pelo tempo, do acesso ao passado que lhe permite compreender o presente e fazer novas escolhas para seu futuro, como o término do relacionamento com Inez e a permanência em Paris.

Meia-Noite em Paris é generoso nos intertextos para que os sentidos da obra sejam estabelecidos. Das personagens históricas às badaladas da meia-noite, que remetem aos contos de fadas; das pinturas, às esculturas e à música. $\mathrm{O}$ enunciador fílmico construído pela narrativa audiovisual posiciona o espectador sob um ângulo que o insere na obra, atribuindo a ele o papel de testemunha do devaneio de Gil. Dessa forma, faz sentido retomar a concepção de nostalgia enquanto elemento da representação identitária, visto que ela emerge mediante a proposição de ruptura com uma visão linear do tempo (BACHELARD, 1994). Importa salientar, ainda, que, segundo essa perspectiva, o tempo é verticalizado e vinculado ao espaço que se torna referencial à construção intelectual que consente o devaneio. É nessa tensão que se dá o transitar de Gil no passado que permite compreender o seu presente; é na tensão do tempo e do espaço que devaneio e nostalgia se imbricam.

A viagem à França inspira Gil a uma reflexão sobre o mundo globalizado onde vive. Conforme os apontamentos de Hall (2003), pode-se perceber que Gil enfrenta uma crise identitária, visto que são expressas diferentes incertezas (BAUMAN, 2007) quanto à carreira, ao amor e aos valores. Gil é roteirista reconhecido em Hollywood, mas anseia tornar-se escritor de romances. Os sentimentos em relação a sua noiva são reconsiderados a partir das experiências com Adriana e dos conselhos de Ernest Hemingway, em alguns dos trajetos ao passado. $\mathrm{O}$ encadeamento dos enunciados evidencia os valores de Gil: amante da história, da política e também das rotinas propiciadas pelo espaço francês. Por outro lado, Inez e seus pais são cativos pelo modo de viver norte-americano, do qual não imaginam ficar distantes por muito tempo. Enquanto eles valorizam o luxo e o alto padrão de 
vida, Gil aprecia as caminhadas, a chuva e os jardins. Diante desse descompasso, o isolamento passa a ser constante durante a estadia de Gil em Paris. Seria o cenário ideal para viver um devaneio, um encontro com a imaginação criadora?

Ilustração 1- Diálogo inicial entre Gil e Inez sobre Paris

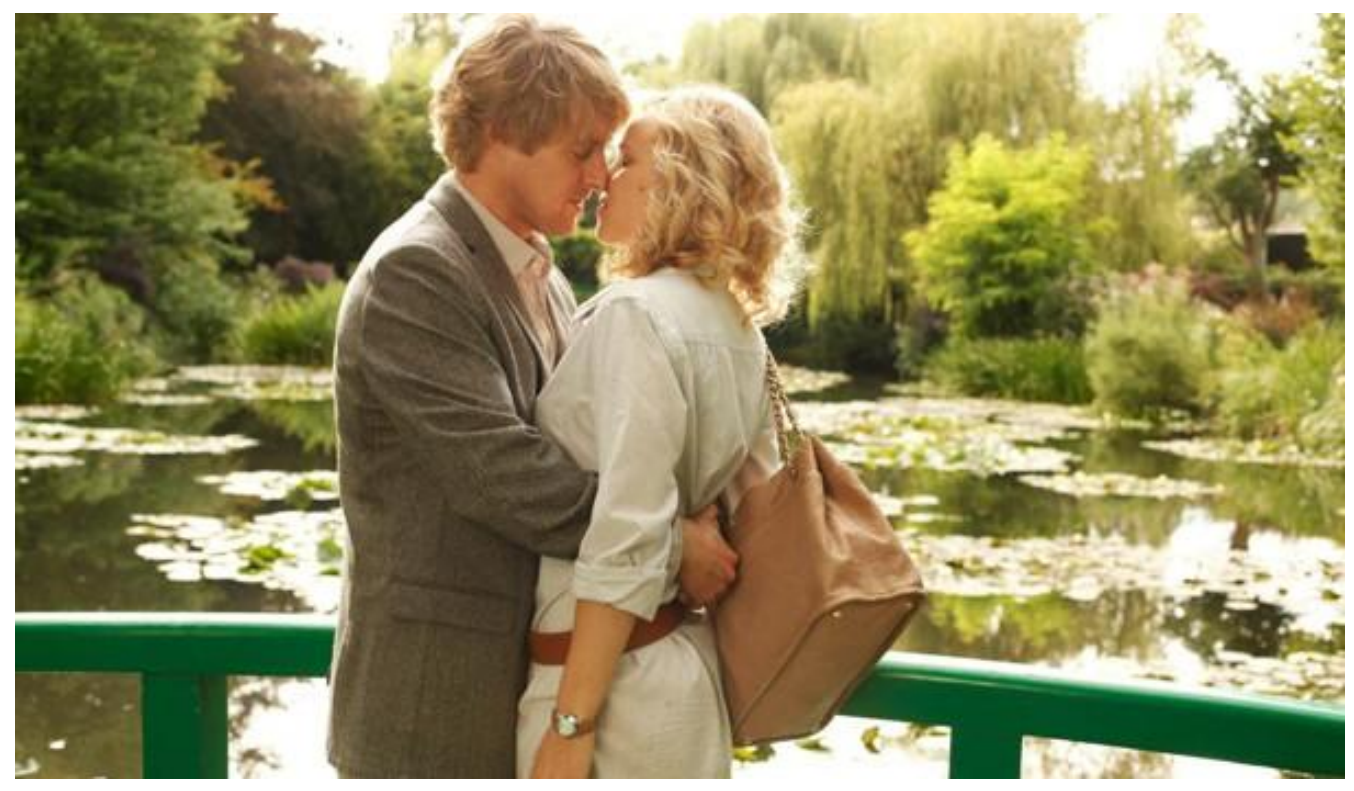

Fonte: Fotograma da produção Meia-Noite em Paris

Diante dos eventos que dão início à crise identitária de Gil, ele passa, então, a ocupar uma posição híbrida (BHABHA, 1998). Esse terceiro espaço (BHABHA, 1998) determina o lócus de enunciação (BAKHTIN, 2015) da narrativa: a cidade Paris, em dois tempos diferentes, o passado e o presente. A leitura das obras de seus "deuses domésticos" (BACHELARD, 1998), como F. Scott e Zelda Fitzgerald, Ernest Hemingway e Gertrude Stein, faz com que Gil construa uma representação de Paris como cidade onde está a liberdade para a produção artística. Por isso, reconhece aquele tempo como mais adequado, seguro e belo, e opta por apoiar-se em tais valores e ideologia, tornando esse o universo que orienta seu agir. A iluminada Paris manifesta-se como oposição ao turbulento cenário americano que suscita o medo e a insegurança quanto à felicidade (BAUMAN, 2007; HALL, 2003). Tal cenário incentiva Gil a questionar as referências de seu tempo e a descentrar-se, ao passo de ingressar uma crise identitária. O questionamento, no entanto, se ancora 
nas projeções por ele efetivadas mediante os relatos de seus antepassados, seus "deuses".

Depreende-se, então, que as opiniões de Gil são fundamentadas, principalmente, na nostalgia, sentimento que o faz vincular-se ao passado. A crença de que o momento descrito nas obras que tanto admira é mais virtuoso do que o atual, inspira o mergulho em si, o questionar-se. Diante da hostilidade de seu contexto e da divergência dele frente a suas formas de interpretar o mundo, Gil efetiva um reencontro com a subjetividade que o conduz ao autoconhecimento. Trata de buscar em sua“casa” (BACHELARD, 1998) a proteção e a liberdade necessárias à sua felicidade.

Ilustração 2- Gil Pender recebe conselhos de Gertrud Stein

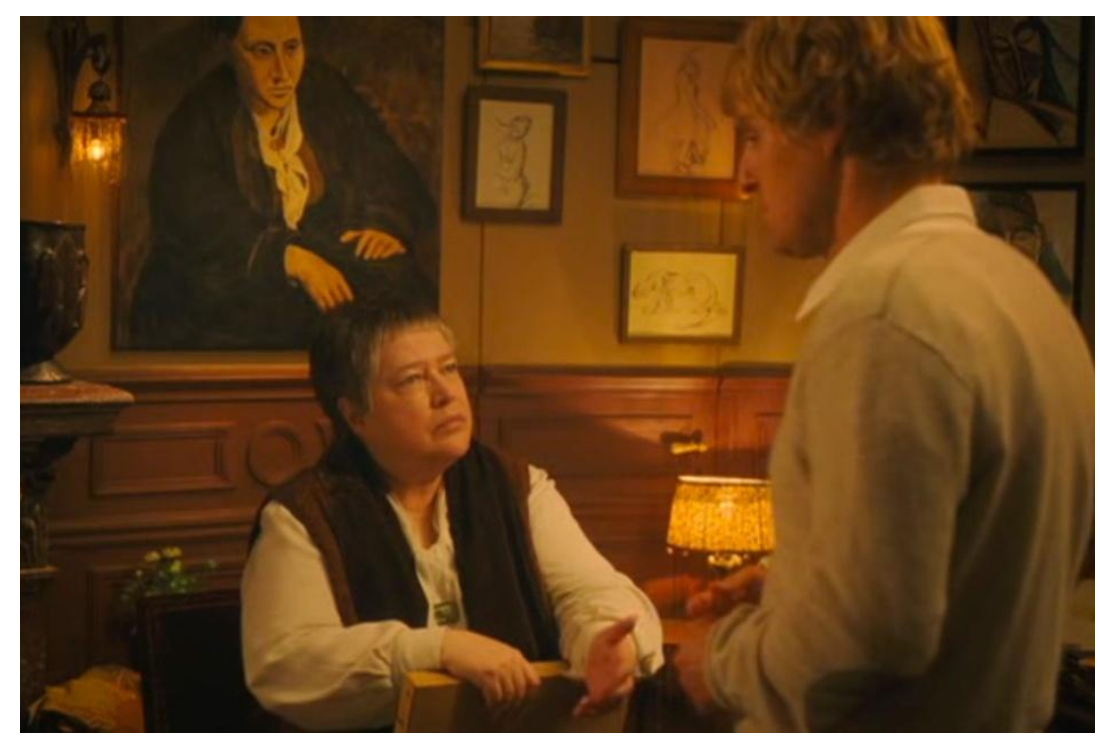

Fonte: Fotograma do filme Meia-Noite em Paris

Assim, é em decorrência da posição híbrida ocupada por Gil que o ingresso a "casa" inicia (BACHELARD, 1998). Para que realize sua viagem interior, Gil depende de um espaço externo que promova seu isolamento, concebido no ponto onde ingressa para sua jornada noturna, no carro misterioso. As doze badaladas demarcam o início de sua viagem aos cantos da "casa”. No sótão, o encontro com os ídolos literários e outros exitosos artistas americanos. $\mathrm{Na}$ direção do porão, o encontro com o amor de Adriana. Durante a estada em Paris, Gil escreve seu livro, seu romance. Entretanto, ele apenas encoraja-se a abri-lona segurança da "casa", 
mostrando-o àqueles em quem confia. As investidas de Inez para leitura desse livro falham. Ela não faz parte da intimidade da "casa" de Gil. De outro modo, Gertrude Stein e Ernest Hemingway têm autorização para lê-lo criticamente. Gil segue somente as recomendações e orientações de seus mestres, os ídolos literários que tão bem conhece, a ponto de neles reconhecer-se. É na “casa”, no percorrer de seus cômodos, que Gil encontra a liberdade para criar os cenários nos quais deseja viver. A imaginação criadora encenada diante do sonho tornado realidade. Eis o devaneio.

A conversão das experiências de isolamento garante a Gil o centramento, a verticalização plena do tempo conjugado, a partir do permear do espaço (BACHELARD, 1998). Trata-se do reencontro com a intimidade que permite a identificação de respostas às suas angústias, ao impasse de sua crise identitária. Ele toma consciência de que projetar o futuro, submetendo-se apenas ao passado, implica em desconsiderar o presente. Essa retomada decorre do escrever e do reescrever de seu livro e expressa o movimento espaço-temporal. A análise do romance que Gil escreve é realizada por seus "deuses domésticos”, que ressaltam uma perspectiva derrotista ali retratada. Ele, então, reconhece-se como personagem principal daquela história:a loja que vende recordações assemelha-se àquela que ele visita com frequência; a traição de Inez. Entretanto,a personagem não atribui sentido a esses eventos até que Gertrud Stein e Ernest Hemingway, em sua crítica literária, apresentem tais evidências. Este é o ponto que demarca a última passagem pelo passado e encaminha o encerramento do devaneio de Gil.

O encontro com as lembranças, construídas a partir das experiências literárias, permite entender a importância da escolha da personagem por vivenciar os dois mundos, do passado de 1920 e o do presente. A contemporaneidade de Gil se estabelece como resultante da memória constituída das percepções advindas das leituras de mundo de artistas do passado. $\mathrm{O}$ choque entre as realidades, a existente na mente de Gil e aquela que se mostra a ele em decorrência da imaginação criadora, conecta-o a outro presente e o mobiliza a reconstruir sua história, sem negar as influências que o constituíram até então, mas as posicionando de outra forma. Trataseda nostalgia enquanto elemento fundamental para a representação identitária. 
Neste momento, a narrativa retoma a linguagem sonora das doze badaladas, que soam como alerta do despertar de Gil, que ao caminhar pela cidade de Paris, reencontra a vendedora da loja de recordações. Demarca-se, então, o recomeço, e pela forma mais poética: a caminhada sob a chuva.

\section{Tempo, espaço e nostalgia: algumas considerações}

A globalização, enquanto processo instransponível e imutável, produz impactos à sociedade. A combinação entre velocidade e espaço, na contemporaneidade,tem implicado uma variada gama de estímulos que ampliam as possibilidades de deslocamento social nesta estrutura. Todavia, tem também ampliado as possibilidades de vínculo identitário, o que leva muitos sujeitos a entrar em um processo de crise, haja vista a confusão referencial para orientação de seu agir. Esse cenário leva ao rompimento com os vínculos de solidariedade, acarreta solidão, individualismo e outras situações de degradação individual e coletiva. O indivíduo necessita buscar alternativas para suprir tais efeitos, a fim de que possa experimentar o mundo com o outro. Nesse sentido, o estudo ora proposto apresenta algumas ponderações para a reflexão acerca da forma como se pode compreender os acontecimentos globais. Para tanto, a suposição tomada como referência tange a fenomenologia bachelardiana que, sob um viés poético, fornece subsídios ao centramento do sujeito na produção de sentidos em seu cotidiano.

Diante do objetivo proposto, percebe-se que a personagem Gil Pender está mergulhada no mundo pós-moderno, caracterizado por Bauman e Hall. Esse contexto faz com que Gil avalie suas escolhas profissionais e amorosas mediante a experiência do devaneio, do acesso aos cantos de sua "casa”. É nesse ponto que a noção de nostalgia passa a ser compreendida pelo tempo e espaço referenciais, cujo transitar verticalizado não está focado em uma sequência lógica de fatos, mas no rememorar dos acontecimentos mediante uma construção intelectual.

Gil passa a olhar para seus valores e retomar suas experiências; passa a olhar para sua trajetória de forma crítica, cujo intuito de ajuste é construído a cada 
revelação da história de sua vida. Depreende-se, então, que o sentimento nostálgico desponta como um modo de representação, já que permite a ruptura com a perspectiva linear e objetiva e evidencia o subjetivo. Assim como Gil vive uma crise identitária diante do contexto hostil que o cerca, por meio do devaneio, ele passa a ocupar uma posição híbrida que oportuniza o vínculo enunciativo entre passado e presente. É diante do movimento da imaginação criadora que ele reencontra a essência de seu ser. Os deuses literários, embora participem do momento de ruptura, são domesticados para o encontro com a realidade, portadora de novos sentidos.

\section{Notas}

[1] Como exemplos: vídeo 236 seconds of Friends divulgado pela Warner Channel, exposição com réplica do "Central Perk", em Nova York, dentre outras atividades.

\section{Referências}

MEIA-NOITE. Direção de Woody Allen. Original: Midnight in Paris, EUA/ESP, 2011.

BACHELARD, Gaston. A casa. Do porão ao sótão. O sentido da cabana. In: .A Poética do Espaço. São Paulo: Martins Fontes, 1998, pp. 23-54. . A Dialética da Duração. 2. ed. São Paulo: Ática, 1994.

BAKHTIN, Mikhail. Os Gêneros do Discurso. In: .Estética da Criação Verbal. 6. ed., p. 259-306. São Paulo: WMF Martins Fontes, 2015.

BAUMAN, Zygmunt. Tempos Líquidos. Rio de Janeiro: Zahar, 2007.

BHABHA, Homi K. O Local da Cultura. Belo Horizonte: Editora UFMG, 1998. FRONCKOWIAK, Ângela Cogo; RICHTER, Sandra. A poética do devaneio e da imaginação criadora em Gaston Bachelard. In:SEMINÁRIO EDUCAÇÃO, IMAGINAÇÃO E AS LINGUAGENS ARTÍSTICO-CULTURAIS, 1, Santa Catarina: Unesc, 2005.

GARDIES, René. Compreender o Cinema e as Imagens. Lisboa: Texto \& Grafia, 2008. 
GAUDREAULT, François; JOST, André. Cinema e Narrativa. In: GAUDREAULT, François; JOST, André. A Narrativa Cinematográfica. Brasília: UNB, 2009. p. 31-51.

HALL, Stuart. A identidade cultural na pós-modernidade. Rio de Janeiro: DP\&A, 2006.

. A Questão Multicultural. In: .Da Diáspora. Belo Horizonte:

Editoria UFMG, 2003. p. 51-100.

LIPOVETSKY, Gilles. A Sociedade da Decepção. Barueri/SP: Manole, 2007. . Os Tempos Hipermodernos. São Paulo: Barcarolla, 2005. 